\title{
DO CUIDAR AO CUIDAR-SE: UM RELATO DE INTERVENÇÃO EM TERAPIA FAMILIAR SISTÊMICA
}

\author{
FROM TAKING CARE TO CARING FOR ONESELF: A REPORT OF AN \\ INTERVENTION IN SYSTEMIC FAMILY THERAPY
}

RESUM0: Este artigo teve por objetivo apresentar uma análise de um processo psicoterapêutico em terapia familiar a partir do referencial teórico da Terapia Familiar Sistêmica com ênfase em uma perspectiva pós-moderna e feminista. Os participantes compõem uma família que foi atendida por uma das autoras. As estratégias, os procedimentos utilizados e as reflexões feitas durante o processo psicoterapêutico possibilitaram mudanças significativas no sistema familiar, o que colaborou para o cumprimento dos objetivos delimitados a partir das expectativas da terapeuta e da família.

PALAVRAS-CHAVE: Processo psicoterapêutico; Família; Terapia Familiar Sistêmica.
ABSTRACT: This article aims to present an analysis of a psychotherapeutic process in Systemic Family Therapy. One of the authors worked with a family of patients who are analyzed in this study. The strategies, the procedures and reflections used during the psychotherapeutic process, brought up important changes in the family system, and made it possible to reach the goals set by the expectations of the Family and the therapist.

KEYWORDS: psychotherapeutic process; family; Systemic Family Therapy.

\section{CLÁUDIA DE \\ OLIVEIRA ALVES}

ANALICE DE SOUSA

ARRUDA VINHAL DE CARVALHO

Universidade Paulista UNIP, Goiânia, GO, Brasil

\section{INTRODUÇÃO}

A partir da década de 1970, o pensamento pós-moderno começa a ocupar um lugar de referência e traz como uma de suas principais características a não aceitação de definições e explicações totalizantes (Grandesso, 2000). Moscheta (2014) enfatiza que a pós-modernidade abre espaço para os múltiplos discursos, legitima as diferenças em nossas descrições de mundo e defende a contextualização histórica e cultural de qualquer afirmação científica. Esse movimento se pauta nos princípios de imprevisibilidade, incerteza e de impossibilidade de um conhecimento objetivo.

As repercussões da pós-modernidade na psicologia brasileira e em especial na prática clínica apontam para a valorização do singular e do contextualmente situado. Os significados, construídos nas relações pessoais, têm lugar de destaque. Na reconhecida obra Sobre a reconstrução do significado: uma análise epistemológica e hermenêutica da prática clínica, Grandesso (2000) apresenta uma interessante análise sobre a virada pós-moderna, com destaque para as epistemologias construtivistas e construcionistas sociais. Essas perspectivas trazem como uma de suas premissas a ideia de que as pessoas se constroem e constroem seu mundo dentro das relações. Destaca-se também a reflexividade e a consideração da base contextual do significado, permeado por sua contínua negociação

Recebido em: 26/02/2018 Aprovado em: 24/09/2018 
(Grandesso, 2000; Moscheta, 2014). O objetivo deste artigo é apresentar reflexões sobre uma experiência de atendimento clínico em Terapia Familiar Sistêmica sob um ponto de vista das críticas pós-modernas e de uma perspectiva feminista.

\section{PERSPECTIVA SISTÊMICA}

A teoria sistêmica surgiu no final da primeira metade do século XX e apontou que o todo não pode ser entendido a partir do desmembramento de suas partes, nem a parte pode ser compreendida de forma isolada. Entre as décadas de 1950 e 1960 nasceu nos Estados Unidos a terapia de família orientada sistemicamente, possibilitando o surgimento de estratégias de intervenção que culminaram nas várias abordagens de atendimento sistêmico, conhecidas hoje como abordagens clássicas da terapia familiar sistêmica (Diniz \& Alves, 2014). Grandesso (2000) aponta que as terapias sistêmicas orientadas pela Cibernética de Primeira Ordem estavam situadas dentro do modelo de pensamento moderno. Os pressupostos pós-modernos aparecem de forma significativa na terapia familiar sistêmica com o desenvolvimento da Cibernética de Segunda Ordem, podendo ser representados pelas epistemologias construtivistas e construcionistas sociais (Narvaz \& Koller, 2007; Paula-Ravagnani, 2015).

As práticas orientadas sistemicamente, ao incorporarem as propostas da Cibernética de Segunda Ordem, apresentaram mudanças significativas no papel de terapeutas familiares e estes passam a ser vistos como integrantes que coconstroem o sistema terapêutico. Essa mudança implicou também a orientação para o presente e a importância da contextualização para se compreender os dilemas humanos. Assim, o comportamento humano passa a ser considerado dentro de um contexto interacional ou interpessoal e os sintomas passam a ser vistos como produtos de inter-relações dentro do sistema do qual fazem parte. Essa nova perspectiva possibilitou a estruturação das terapias sistêmicas construtivistas e construcionistas sociais, representadas nos modelos conversacionais, dialógicos ou narrativos. Os sistemas humanos passaram então a ser compreendidos como sistemas linguísticos, como é proposto principalmente pelo construcionismo social (Grandesso, 2000).

A função performática da linguagem é valorizada pelo construcionismo social como produtora de descrições de si e de modos de ação. De acordo com Corradi-Webster (2014, p. 81 ), "os discursos são o pano de fundo conceitual no qual baseamos nossas afirmativas e sentidos, com os quais compreendemos o mundo e nossas experiências e construímos nossas práticas". À medida que se considera que a linguagem constrói realidades, é possível então fazer uma avaliação crítica das formas de vida que ela constrói. A experiência pessoal é entendida como um discurso e o self como uma construção social. Ou seja, vocabulários que utilizamos para nos referirmos a nós mesmos legitimam e sustentam práticas culturais específicas e impedem outras formas de construção de identidade (Souza, 2014). A partir de um enquadramento criado pelos discursos, certos modos de vida são restringidos e outros estimulados (Moscheta, 2014). Corradi-Webster (2014) aponta que os discursos mais hegemônicos terão mais chances de impactar a construção das subjetividades e de balizar modos de se relacionar. $\mathrm{O}$ discurso construcionista social valo- 
riza os processos relacionais (Souza, 2014). Nessa perspectiva, a experiência humana é construída em um contexto histórico, cultural e linguístico. As ideias, os conceitos, as recordações surgem na interação social e se expressam na linguagem e no diálogo. Em vez de um reflexo de processos inerentes à psique individual, nossa experiência de mundo interno é moldada na atividade da fala entre indivíduos (Grandesso, 2000). Em consonância com a perspectiva feminista, o construcionismo social na clínica permite levar questionamentos críticos para o setting terapêutico, fazendo uma aproximação entre a crítica social e a prática clínica (Guanaes-Lorenzi, 2014).

\section{PERSPECTIVA FEMINISTA}

Entre as décadas de 1970 e 1980 surgiram críticas direcionadas aos pressupostos das abordagens em terapia familiar sistêmica. Essas críticas, em grande parte feitas pelo movimento feminista, apontavam que a postura da terapia familiar sistêmica muitas vezes ignorava ideologias e os contextos sociais e políticos nos quais as pessoas estavam inseridas (Narvaz \& Koller, 2007). Autoras como Virginia Goldner, Marianne Walters, Betty Carter, Peggy Papp e Olga Silverstein podem ser consideradas pioneiras na discussão da integração da perspectiva sistêmica com a perspectiva feminista (Greene \& Bogo, 2002). A perspectiva feminista traz para a teoria sistêmica problematizações sobre ideologias e contextos sociais e políticos nos quais as pessoas vivem (Diniz \& Alves, 2014). O feminismo pode ser entendido como um movimento que busca promover reflexões sobre as condições de mulheres e homens na sociedade em diversos momentos históricos, e luta para diminuir a desigualdade entre homens e mulheres, tanto na esfera pública quanto privada. Apesar de existirem muitos tipos de feminismos (liberal ou reformista, radical, socialista, mulheres de cor ou "womanism", cultural, pós-colonial, dentre outros), a valorização da experiência das mulheres e o reconhecimento da necessidade de mudança social são o que há em comum nessa diversidade (Alves, 2013).

A perspectiva feminista na psicologia é recente (Worell \& Johnson, 2001). As filosofias feministas focam no impacto de dimensões do contexto social e político nas vidas de mulheres e homens e propõem a mudança social como forma de melhorar sua qualidade de vida e saúde mental (Evans, Kincade \& Seem, 2011). Uma intervenção psicológica com perspectiva feminista implica que o/a psicólogo/a que realiza esse tipo de intervenção problematize as questões de gênero e reconheça que elas não devem ser pensadas desvinculadas de marcadores sociais como classe, gênero, cultura, raça/ etnia, momento histórico e aspectos políticos e econômicos. Considerar as construções de gênero e o poder nas relações, utilizar métodos de desmistificação dos processos naturalizantes e o ativismo social são técnicas comumente utilizadas por terapeutas feministas (Neves \& Nogueira, 2004). Caracteriza-se também por uma escuta diferenciada e não se pauta na tentativa de adaptar as pessoas a determinadas ideias de gênero. Em vez disso, cria outras possibilidades de ser para além das prescrições de gênero. A relação entre terapeuta e cliente é baseada na igualdade e se considera a história e a política para a compreensão da construção das subjetividades. Alguns dos resultados de intervenções relatados por psicólogas que trabalham com essa perspectiva no Brasil foram: re- 
dução de danos, alívio de pessoas que se sentem oprimidas e potencialização das mulheres (Alves, 2013).

As reflexões feministas possibilitaram o surgimento do conceito de gênero e uma das autoras a definir esse conceito foi Joan Scott (1995). No artigo intitulado Gender: A useful category of historical analysis, publicado pela primeira vez no ano de 1985, a autora propôs gênero como uma categoria de análise das relações sociais. Construído socialmente, ele define as relações sociais e se refere às expectativas para comportamentos e atribuições (Couto-Oliveira, 2007; Diniz, 1999, 2004; Perelberg, 1994), mas essas prescrições e expectativas tomaram caráter de leis sociais (Giffin, 2005) e estão presentes em todas as dimensões da vida dos indivíduos. A incorporação do termo gênero serviu para analisar a subordinação das mulheres a partir das relações sociais e a consequente produção da sexualidade e do próprio gênero (Mayorga, Coura, Miralles, \& Cunha, 2013). Nessa mesma direção, Butler (1990/2014) propôs a desconstrução de gênero como derivado do sexo biológico a partir da noção de que o próprio sexo também é construído. A partir dessa compreensão, a própria ideia de identidade de gênero foi colocada em xeque.

Estereótipos de gênero associados a expectativas e comportamentos culturalmente considerados adequados para homens e mulheres contribuem para a construção da noção de si. A noção de si aqui está sendo entendida como não estável, plural e situada, assim como Davies e Harré (1990) propuseram pensar em posicionalidade. Os estereótipos de gênero são diferentes para homens e mulheres. Aqueles vinculados às mulheres as desqualificam e inferiorizam por sua atuação nas relações familiares, sociais e no trabalho, enquanto aqueles vinculados aos homens assinalam qualidades emancipatórias e de comando nas relações sociais (Couto-Oliveira, 2007). Valores e estereótipos de gênero que são partilhados culturalmente estão fortemente presentes nas experiências e na fonte de sofrimento psíquico grave de homens e mulheres (Zanello, 2010; Zanello \& Bukowitz, 2011).

Diante do exposto, o referencial teórico adotado pelas autoras está localizado no movimento pós-moderno e parte dos seguintes reconhecimentos apontados por Walters (1994): das mensagens de gênero e dos construtos sociais que condicionam o comportamento e as construções sexuais; das limitações reais de acesso das mulheres aos recursos econômicos e sociais; das marcas do sexismo que limitam as opções das mulheres para dirigirem suas próprias vidas; que as mulheres são socializadas para assumirem responsabilidade pelas relações familiares; das dificuldades, dilemas e conflitos relacionados ao ter e criar filhos em nossa sociedade e afirmação dos valores e comportamentos característicos das mulheres, tais como a capacidade de conectar, cuidar e nutrir emocionalmente.

Em relação à família, esta é entendida como um sistema aberto, em permanente transformação, e passa a ser pensada para além da ligação de parentesco. Há também a mobilidade na consideração de quem pode fazer parte da terapia (Grandesso, 2000). Narvaz e Koller (2007, p. 123) salientam que os problemas trazidos pelas famílias, longe de serem entendidos como disfunções, são vistos "como narrativas ou descrições rígidas e estáticas que a família constrói sobre suas relações. O papel do terapeuta é auxiliar a família a ampliar tais descrições através de novas narrativas que são co-construídas 
no sistema terapêutico". A partir do referencial teórico explorado, o presente artigo discute um caso de atendimento em terapia familiar.

\section{METODOLOGIA}

Este artigo integra relato e análise do processo de um atendimento clínico em terapia familiar. O levantamento do material clínico foi realizado por meio da leitura do prontuário e de anotações das sessões. Ao total foram 13 sessões, com frequência semanal, que aconteceram entre os meses de maio e outubro do ano de 2015. Imediatamente após as sessões, que tiveram duração média de uma hora e meia, foram realizadas anotações detalhadas sobre o processo terapêutico. No espaço terapêutico foram utilizadas estratégias como perguntas circulares, perguntas reflexivas, devolutivas, uso de metáforas, dentre outras. O processo terapêutico foi analisado a partir do referencial teórico adotado. Todos os membros da família autorizaram a utilização dos dados para a realização do estudo por meio de Termo de Consentimento Livre e Esclarecido. Foram utilizados nomes fictícios para preservar o sigilo da identidade dos participantes.

\section{Apresentação da Família}

Os participantes do processo terapêutico familiar integram uma família monoparental atendida pela primeira autora. Participaram do processo terapêutico Maria (presente em 12 sessões), Carla (presente em 13 sessões) e Lucas (presente em 12 sessões). A família foi encaminhada por uma instituição educacional em que Lucas é atendido.
Maria, aposentada, tinha 65 anos de idade na data do início do processo terapêutico. Ela é mãe de Carla e de Lucas e todos residiam na mesma casa. Maria também tem um filho mais velho, Alex, que é casado e morava em outra casa. Maria foi casada até o nascimento de Lucas, quando o casal se separou por iniciativa do ex-marido. Maria criou os três filhos sozinha e não teve ajuda do ex-marido. Ela também não teve outro relacionamento amoroso desde então. Maria tinha apenas o que corresponde ao ensino médio e trabalhou fora de casa desde a separação. Ela estava aposentada há três anos e era a responsável pelo cuidado da casa.

Carla, a filha do meio, tinha 39 anos de idade no início do processo terapêutico. Ela tinha ensino superior completo e era quem provia a maior parte do sustento da família. Durante a sua vida, ela morou em outra casa por cinco anos. O que motivou a saída de Carla de casa foi a relação difícil com o irmão Lucas. Os dois brigavam muito e chegaram a se agredir fisicamente. Carla contou que o período em que ficou fora de casa foi muito ruim porque via Maria e Lucas passarem por dificuldades. Alex também a ajudava a cuidar da família, mas depois que se casou ficou mais afastado. Dos cinco anos que morou fora, Carla ficou seis meses com o pai e a esposa dele. Apesar de sempre ter se dado bem com o pai, ela contou que foi um período muito difícil, pois teve dificuldade de ficar no que ela nomeou de papel de filha. Carla mencionou que sempre gostou de estar no controle, de cuidar, mas que na casa do pai ela não tinha esse espaço. Assim, acabou voltando a morar com a mãe e o irmão. Carla nunca se casou e seus relacionamentos amorosos tiveram em geral pouca duração. 
Lucas, o filho mais novo, no início dos atendimentos tinha 36 anos de idade. Ele não terminou a educação básica e no momento não estava trabalhando. Ao nascer, Lucas engoliu água da placenta. Aos cinco anos de idade foi diagnosticado com Discalculia e Distimia. Maria buscou apoio profissional para o filho e desde então ele fazia acompanhamento médico, psiquiátrico, psicológico, dentre outros. No período da terapia familiar Lucas estava fazendo uso de antidepressivo. Ele frequentava uma instituição educacional e terapêutica há mais de 20 anos. Já tivera alguns empregos, mas não duraram muito tempo. Maria sempre se dedicou aos cuidados de Lucas e relatou que sempre o protegeu do sofrimento e o cercou de muitos cuidados.

No momento em que procurou atendimento, a família desejava mudar o relacionamento entre eles, que, segundo Maria e Carla, estava muito difícil. A família veio para a terapia apontando Lucas como a fonte das dificuldades relacionais entre eles. Lucas já foi acompanhado por psicólogos em vários momentos de sua vida. Carla já fez terapia individual uma vez. Maria, apesar de ter tido muito contato com os/as psicólogos/as de Lucas, nunca havia feito terapia.

\section{DISCUSSÃO}

\section{0 processo da terapia}

A terapia com a família teve duração de cinco meses e meio e foram realizadas 13 sessões semanais. Os objetivos terapêuticos estabelecidos foram: contribuir para a mudança no padrão relacional familiar; promover o empoderamento e reconstrução da autoesti- ma dos membros da família; provocar reflexão sobre a dinâmica relacional e sua relação com o sistema sexo/gênero.

Para atingir os objetivos, foram adotadas como referencial sistêmico orientador as propostas relativas às práticas pós-modernas enquanto contexto gerador de alternativas (Grandesso, 2000). Nessa perspectiva, o terapeuta passa a ser encarado como um facilitador, um agente de transformação social. A terapia, um sistema terapêutico do qual o terapeuta também é parte, é entendida como um contexto dialógico que possibilita transformações.

A terapia familiar foi realizada somente com uma terapeuta. Não se fez uso de coterapia e equipes reflexivas. Os múltiplos olhares sobre o caso foram mantidos por meio de supervisões e discussões com outros profissionais. Essa proposta está em harmonia com a perspectiva pós-moderna de criação de novas práticas que permitam a ampliação das possibilidades de condução de terapia para além da proposta de terapia sistêmica tradicional. A terapia individual de orientação sistêmica proposta por Boscolo e Bertrando (2008) é outro exemplo de prática sintonizada com a perspectiva pós-moderna. $\mathrm{O}$ processo terapêutico foi explorado e dividido em três momentos: primeiras sessões, sessões intermediárias e sessões finais.

\section{Primeiras sessões}

As estratégias terapêuticas iniciais focaram na construção do vínculo terapêutico e na identificação das demandas trazidas pela família. Foram utilizadas perguntas circulares combinadas com um espaço flexível de fala para cada membro da família. Maria e Carla apontavam Lucas como o centro da queixa. Carla comentou que com o 
tempo tem aprendido a conviver com o irmão, mas gostaria que o relacionamento entre os dois fosse melhor. Lucas também afirmava que o relacionamento entre eles não era muito bom.

Lucas foi tratado como "deficiente" pela família desde que recebeu os diagnósticos. Ele próprio utilizava o termo "deficiente" muitas vezes para se referir a si mesmo, apresentando uma construção da noção de si pautada nesse rótulo. A terapeuta propôs a troca da palavra "deficiente" pela expressão "com algumas dificuldades". Considerando que o sentido não reside nas palavras, mas vai se construindo na conversação (Grandesso, 2000), a intervenção teve o objetivo de propor reflexão sobre um conceito cristalizado no qual predominava o sentido de incapacidade.

O processo terapêutico deu-se buscando proporcionar novos sentidos e novos significados para a queixa e para as relações entre os membros da família. Isso possibilitou que as histórias de Maria e Carla também aparecessem como elementos no sistema terapêutico. Maria relatou que se deu conta de que viveu a vida somente para os filhos. Ela mencionou que quando Lucas fez 30 anos ela percebeu que não tinha vivido sua vida. Agora, com 65 anos de idade, começou a perceber que está caminhando para o fim da vida. Maria interditou judicialmente o filho para, segundo ela, garantir que ele receba sua aposentadoria quando ela morrer.

As relações familiares apontaram para uma grande dependência de Lucas em relação à Carla e, principalmente, em relação à mãe. Era possível notar que Lucas apresentava uma narrativa dominante e rígida sobre determinados valores e sentidos dados às suas relações em família. Seu discurso era de culpabilização de sua condição financeira por toda sua infelicidade. Nesse sentido, culpava Maria por não conseguir garantir o padrão de vida que ele desejava ter. Lucas não apresentava desejo de mudança a não ser de sua condição financeira.

Nas duas primeiras sessões Lucas permaneceu calado grande parte do tempo. Quando a terapeuta direcionava a fala para Lucas, a mãe o interrompia e quase não o deixava falar. Em muitos momentos Maria explicava para o filho o que estava sendo dito, apesar de ele não solicitar. Maria agia como se ele não fosse capaz de entender. A dinâmica relacional da família não possibilitava uma escuta colaborativa e o diálogo, nem a expressão de diferentes sentidos e significados sobre o vivido. $\mathrm{O}$ fato de Lucas não falar colocava-o em um lugar na relação, da mesma forma que, ao falar por ele, Maria se colocava em um outro lugar nessa mesma relação. Estabelecia-se, assim, um padrão de comunicação específico entre eles.

Uma das queixas trazidas nas sessões foi nomeada pela família como "falta de diálogo" entre eles. Carla e Maria comentaram que muitas vezes "não desejavam nem bom dia" uns aos outros e que elas gostariam que isso acontecesse. Diante disso, com a intenção de introduzir um elemento novo na comunicação da família fora do setting terapêutico, foi sugerido pela terapeuta que cada membro da família desejasse "Bom dia!" ao outro durante a semana que se seguisse. Carla comentou que começou a desejar "Bom dia!" ao irmão pela manhã e que ela se sentiu muito bem ao ouvi-lo responder.

Foi incentivado que Carla, Maria e Lucas estabelecessem diálogos durante os atendimentos. Nas primeiras sessões, Maria foi quem mais reivindicou o espaço de fala. Assim, o contexto terapêutico estava funcionando como 
um espaço generativo de novas possibilidades comunicacionais, pois posteriormente Maria comentou o fato de que nunca havia falado tanto.

$\mathrm{Na}$ terceira sessão Maria trouxe relatos sobre a relação com o ex-marido e a separação do casal. Ela relatou estar sendo muito bom participar da terapia, pois estava tendo a oportunidade de dizer para os filhos coisas que ela nunca havia dito, como, por exemplo, o relato sobre a separação. As pessoas criam histórias de suas experiências para construir sentido e contextualizar a vida. Como apontam Martins, Santos e Guanaes-Lorenzi (2014, p. 157), "isso quer dizer que as histórias são compreendidas como constitutivas da vida das pessoas. Ao contar histórias sobre si mesmas e sobre o mundo, as pessoas estão produzindo narrativas que organizam suas vidas". As histórias que Maria contava apenas a si mesma agora estavam situadas no contexto de diálogo do sistema terapêutico e abriam a possibilidade de construção de novos sentidos (Grandesso, 2000; 2009).

Em um momento da sessão Carla disse se sentir culpada por somente a mãe estar fazendo a organização da casa. Então, a terapeuta convidou Maria a dizer algo para a filha. Dirigindo-se à Carla, Maria disse que entendia que não era culpa dela, pois ela trabalhava muito e já ajudava financeiramente. Maria ainda acrescentou que desejava que a filha não ficasse sem ter vivido a vida como ela. Na sessão seguinte Carla se sentou em um lugar diferente e relatou que as duas semanas que se passaram foram muito boas. Disse que conseguiu arrumar a casa e isso a deixou feliz. Ao explorar o que foi diferente, Carla comentou que o apoio da mãe foi muito importante.

Diante da autoestima reduzida dos membros da família, chegou-se, junto com a família, à criação da proposta de que cada um fizesse algo de bom para si mesmo durante a semana. Essa intervenção teve o objetivo de fazer com que cada um cuidasse mais de si mesmo, possibilitando o aumento de autonomia. Nas duas primeiras semanas eles afirmaram não terem conseguido realizar a proposta. Carla e Maria disseram que iriam continuar tentando. Foi pontuado pela terapeuta que nenhuma mudança é fácil.

\section{Sessões intermediárias}

As sessões seguintes tiveram o objetivo de possibilitar um contexto terapêutico onde a família pudesse construir narrativas com mais possibilidades relacionais. Buscou-se a ampliação das histórias convidando os participantes a olhar de outra forma para si mesmos e para a família como um todo.

Em determinado momento, Carla se dirigiu a Lucas e fez uma reclamação dizendo que não estava conseguido dormir bem à noite porque ele ficava fazendo muito barulho. Lucas afirmou que a culpa era de Maria por fazer o almoço tarde e alterar seus horários de alimentação e sono. Maria disse reconhecer que estava errada. Diante dessa situação, a intervenção foi realizada no sentido de propor uma reflexão sobre a interligação entre eles, para que pudessem perceber que o fazer de um interferia no que o outro estava considerando como incômodo. Foi sugerido abandonar a perspectiva de culpa e pensar na corresponsabilidade de todos.

Maria respondia por Lucas em alguns momentos das sessões. Isso demonstrava o quanto ela ainda não conseguia possibilitar que ele falasse por si mesmo. Em vários momentos 
isso foi pontuado e a terapeuta abriu espaço para Lucas falar por si. A seguinte pergunta reflexiva foi utilizada: Maria, será que o fato de você falar pelo Lucas não o impede de aprender a se expressar? Maria concordou e fez uma expressão que foi entendida como sendo de reflexão. Grandesso (2000; 2009) apontou que uma pergunta abre um universo de possibilidades. Não se sabe onde é que uma pergunta vai chegar. Uma boa pergunta não é aquela que provoca boas respostas, mas aquela que permite que a pessoa possa gerar reflexões também em outros momentos. Pelo que foi aparecendo ao longo do processo terapêutico, acredita-se que essa pergunta contribuiu para que Maria refletisse sobre essa questão.

O uso de metáforas no processo terapêutico é um recurso útil para a construção de significados. Paschoal e Grandesso (2014, p. 25) apontam que metáforas podem ser utilizadas com objetivos diversos, por exemplo "quando alguma imagem ou história nos vêm à mente ao escutar nossos clientes, oferecendo uma possibilidade de sentido para apreciação dos envolvidos no processo". Durante a quinta sessão, foi utilizada a seguinte metáfora com a família:

Terapeuta: Ao longo desse tempo que estamos juntos e diante de tudo o que vocês compartilharam comigo, a imagem que me vem à cabeça é que vocês duas (referindo-se à Carla e Maria) estão carregando Lucas no colo o tempo todo.

Mãe e filha acenam com a cabeça em sinal de confirmação e a terapeuta continua:

Terapeuta: Mas se ele ficar no colo o tempo todo, como é que ele vai aprender a andar?
Maria relatou que desde que Lucas era criança ela se apegou aos rótulos do diagnóstico de Discalculia e Distimia. Outros profissionais já sinalizaram que ela poderia agir diferente com o filho. Antes ela sentia raiva por dizerem que ela tinha que mudar. Maria afirmou que é assim que ela sabe ser, disse se arrepender e se culpava por não ter pedido ajuda do pai dos filhos para criá-los. Buscando novos olhares para aquela situação trazida, foi perguntado se ela fez o que ela sabia e conseguia fazer no momento. Maria disse que sim. Em momentos posteriores ela voltou a se referir a isso como um erro. Grandesso (2000) aponta que entre ser tocado e colocar na linguagem às vezes leva um tempo.

Maria perguntou se a terapeuta acreditava ser possível Lucas mudar, ou se ela teria que se conformar. Imediatamente Carla disse saber a resposta, e afirmou que seriam elas que teriam de mudar, viver as próprias vidas e deixar Lucas viver a dele. Carla estava aos poucos apresentando novas compreensões das relações sistêmicas interpessoais.

Em famílias monoparentais que configuram um grande envolvimento entre os membros, como é o caso dessa família, um objetivo do processo terapêutico pode ser o de identificar os recursos de cada um. Seguindo essa proposta, no final da quinta sessão a terapeuta pediu para que cada membro da família identificasse uma qualidade que acha positiva nos outros membros e em si mesmo. Ainda foi proposto que cada um pensasse no que eles poderiam fazer para cuidar de si mesmos.

Em outra sessão, Carla comentou que estava de férias e desta vez estava sendo diferente para ela. Há três anos tudo o que ela fazia nesses períodos era dormir muito e mencionou que 
talvez fosse fuga. A terapeuta a convidou para uma reflexão sobre isso. Carla disse que talvez fosse fuga de viver. Logo em seguida ela relata que agora está com mais energia, está saindo com as amigas e afirmou que isso estava sendo muito bom. Carla não sabia dizer o que mudou, mas percebia que estava diferente. Diante das mudanças, de alguma forma ela estava se abrindo para outras relações com outras pessoas e consigo mesma, construindo, assim, possibilidades diferentes.

Carla foi convidada pela terapeuta a imaginar que Lucas fosse independente. Questionada sobre o que mudaria para ela, Carla disse que ela também seria mais independente e gostaria de comprar o próprio carro. A partir dessa intervenção foi possível ajudar Carla a pensar nas consequências de mudanças nas relações familiares. Ela também disse não ter vontade de ter filhos e acha que não formaria outra família se não tivesse que cuidar de Maria e Lucas. Faz parte da perspectiva feminista o reconhecimento e apoio às possibilidades que existem para as mulheres de obterem realização e de terem uma vida plena além do casamento, da maternidade e da vida familiar (Walters, 1994). Em seguida Carla disse que já se sente casada e com filhos:

Carla: É como se eu já fosse casada e tivesse filhos.

Terapeuta: Casada com quem? Quem são seus filhos?

Carla: Mas é como se eu já tivesse. É como se minha vida não tivesse lugar para outra pessoa.

O sentido que Carla atribui a relacionamentos foi explorado. Para ela, relacionamento sério significava mais uma pessoa para ela cuidar. Carla nun- ca teve nenhuma relação duradoura. Sempre que o namoro começava a ficar mais sério ela terminava. Para ela já era muito cuidar da mãe e de Lucas. O cuidar esteve presente na vida de Carla desde quando ela se lembrava. Importante salientar que o cuidado faz parte do estereótipo de gênero socialmente considerado adequado para as mulheres (Diniz, 1999). Desde muito cedo são transmitidas, para mulheres e homens, mensagens que relacionam o ser mulher ao "ter que cuidar". Ao longo da vida, para corresponder a essa expectativa muitas mulheres acabam negligenciando o próprio cuidado. Esse pareceu ser caso de Carla.

Durante o processo de terapia Carla foi percebendo que a mãe e o irmão poderiam se cuidar e que ela também precisava cuidar dela mesma. No final da sétima sessão Carla contou com entusiasmo que há uma semana comprara sapatos novos para ela, algo que não fazia há muito tempo. Disse que isso a deixou muito feliz. Carla estava assumindo uma postura ativa no seu próprio cuidado.

Fazer com que também Maria se tornasse agente ativa no próprio cuidado e melhorasse sua autoestima e autovalorização foram também objetivos da terapia. Ao se comparar às irmãs, principalmente em relação à situação financeira, Maria chegou a afirmar que ela "não é nada”. Quando questionada pela terapeuta quando foi que ela começou a achar que não era nada, Maria se mostrou surpresa pelo que disse e afirmou que não era bem assim. Quando a expressão aparece no seu próprio discurso, Maria não sente estranheza. A intervenção da terapeuta gerou estranheza e possibilitou uma reflexão.

Após investigar como Maria via as mulheres de sua família, ela disse que elas são fortes e guerreiras. Depois de fazer um relato de como criou os três 
filhos sozinha, Maria disse que ela também era guerreira. Diante da expressão do conceito subjugado que Maria tinha de si, o objetivo foi fazer com que ela conseguisse olhar para outros aspectos de sua história, ampliando-a.

Maria foi convidada a olhar para si de outra forma por meio de perguntas que convidavam à reflexão. Ela é uma mãe que sempre se dedicou integralmente e somente aos filhos. Ao mesmo tempo em que Maria é mãe, ela também é mulher, trabalhadora, ex-funcionária, etc. Mas em suas narrativas estava presente somente a Maria mãe, que se doava por completo aos filhos, chegando a se anular como mulher, chegando a comentar que a Maria mulher estava "morta". Uma intervenção foi feita com o objetivo de gerar a possibilidade de novos modos de ela se relacionar consigo mesma. Uma reflexão conjunta permitiu a troca da palavra "morta" por "adormecida". Os membros da família foram convidados a pensar em como Maria poderia despertar a mulher que existe nela. Vianna (2012), partindo para a perspectiva feminista, destaca que dar voz às mulheres pode promover saúde mental.

A terapia para Maria foi um espaço onde ela pôde ter voz. Maria nunca havia conversado com os filhos sobre a separação. Quatro dias antes de uma das sessões, quando o filho mais velho perguntou sobre o motivo pelo qual o pai foi embora, ela conseguiu conversar com ele. As mudanças apresentadas por Maria foram encaradas como um empoderamento possibilitado por uma postura sensível ao que Diniz (1999) apontou como Condição Feminina. Um pouco antes de acabar uma sessão, Maria comentou:"Eu tenho que dizer uma coisa. A terapia está sendo muito boa. E sabe por que está sendo muito boa? Porque eu nunca falei. Isso tudo que eu falo aqui, os meus filhos não sabiam".

$\mathrm{Na} 10^{\mathrm{a}}$ sessão Lucas comentou que surgiu uma nova oportunidade de emprego. Ele não considerava que essa era a oportunidade de sua vida, mas que era melhor do que ficar sem fazer nada. Lucas já não parecia tão rígido como nas primeiras sessões. Ao ser questionado sobre o que ele poderia fazer para o emprego dar certo, ele afirmou que poderia se esforçar mais para cumprir os horários e não ficar reclamando tanto. Lucas já conseguia reconhecer sua parcela de responsabilidade em relação ao emprego, diferente da postura anterior de culpabilização dos outros por não considerarem o que ele chamava de "deficiência".

Carla e Maria começaram a agir de forma diferente com Lucas. Não estavam mais colocando-o no centro e percebiam mudanças nas relações entre eles. Aos poucos a dinâmica familiar parecia se tornar diferente. Maria passou a confiar mais em Lucas e mencionou que Carla e Alex sempre foram muito responsáveis e agora ela estava começando a achar que Lucas também é, na medida em que ele pode. Para a perspectiva construcionista social a mudança está relacionada à construção de novas narrativas deslocando do discurso do problema individual para uma compreensão da responsabilidade compartilhada, o que permite novas posições para todos os envolvidos (Rasera \& Guanaes, 2010). Esse processo estava acontecendo na terapia.

\section{Sessões finais}

Nas últimas sessões, as conquistas ocorridas ao longo do processo terapêutico foram discutidas. $\mathrm{Na} 11^{\mathrm{a}}$ sessão a família foi convidada a refletir e conversar sobre seu percurso 
no processo terapêutico. Maria disse perceber Lucas mais carinhoso com ela e apontou que o relacionamento entre os dois tem mudado para melhor. Ela ainda comentou que com a terapia ela conseguiu falar mais, se expressar mais e olhar um pouco para ela. O fato de estar envelhecendo foi fonte de preocupação para Maria. Ela disse que estava conseguindo lidar mais com essa questão, pois começava a achar que, se ela morrer, Lucas conseguiria se cuidar. Lucas pontuou que tem gostado do fato de Maria estar saindo mais de casa. Carla mencionou estar achando a terapia muito boa, pois o relacionamento entre eles melhorou e ela passou a viver mais a vida dela. Com o objetivo de possibilitar perspectivas de manutenção das mudanças no futuro, a família foi incentivada a pensar e dizer o que espera para eles no futuro.

Maria ainda tentou explicar a Lucas o que a terapeuta dizia, mas em uma medida muito menor que a percebida no começo da terapia. Acredita-se que será uma mudança gradual. Grandesso (2000) assinala que sempre mudamos e ao mesmo tempo continuamos um pouco os mesmos. Permanecer um pouco os mesmos é o que possibilita nos reconhecermos.

$\mathrm{Na} 12^{\mathrm{a}}$ sessão foi feita uma devolutiva com a família. A partir do que foi trazido e trabalhado ao longo das sessões, a família foi convidada a ajudar na construção de um quadro onde se procurou resumir e exemplificar as mudanças ocorridas até o momento. A coconstrução do quadro possibilitou reflexões de como cada membro chegou e como estava no momento. No final, também foi discutido como a família iniciou o processo terapêutico. Para a avaliação de como a família estava no momento também houve um espaço aberto para que eles pudessem dizer como a estavam percebendo. Seguem as reflexões presentes no referido quadro.

Maria chegou querendo mudar Lucas. No final do processo ela estava confiando mais na autonomia do filho; estava percebendo que só conseguiria mudar a si mesma; conseguiu falar de si e olhar mais para ela mesma. Lucas iniciou o processo com uma postura muito rígida e um pouco indiferente ao sofrimento da família. No momento estava começando a assumir uma postura de maior responsabilidade; estava considerando mais a mãe e a irmã. Carla chegou totalmente voltada para o cuidado de Maria e Lucas. Ao longo da terapia ela começou a olhar mais para si mesma; estava percebendo que pode cuidar do outro, mas também é importante cuidar de si mesma. A família como um todo chegou querendo mudar Lucas e o relacionamento entre os membros. Maria, Carla e Lucas disseram perceber que o relacionamento entre eles mudou para melhor. A mudança nos sentidos e significados dados à dinâmica relacional e à forma comunicacional entre os membros da família também foi pontuada pela terapeuta, uma vez que estavam conseguindo estabelecer espaços de fala e escuta menos monopolizados.

Carla comentou que desde o momento em que soube que seria terapia de família e entrou na sala pela primeira vez, já começou a refletir. Comentou ainda que houve muita mudança ao longo do processo e que agora ela iria pensar nela também. Maria foi encaminhada para terapia individual. Lucas também vai continuar com a terapia individual que havia sido interrompida quando a terapia de família iniciou. A terapia individual não foi indicada para Carla. Ela confirmou que, no momento, não sentia necessidade. 
A última sessão realizada aconteceu um mês depois do último encontro. Desta vez, foi Lucas quem começou a falar. Ele disse estar bem e que foi o destaque do mês no trabalho. Maria ouviu Lucas falar e não o interrompeu na maior parte do tempo. Foi a primeira vez que Lucas iniciou a sessão. Maria relatou estar cuidando mais dela, pensando mais nela. No início da última sessão Maria e Carla se sentam em um sofá grande, uma em cada ponta, e Lucas em uma poltrona. Quando Maria começa a falar, Lucas se levanta e senta no meio do sofá, entre a mãe e a irmã. Foi a primeira vez que todos se sentaram no mesmo sofá.

Carla, há dois meses, estava se relacionando amorosamente com uma pessoa. Fazia oito anos que ela não se relacionava com ninguém. Comentou temer que o fato de ele ser mais novo que ela poderia ser um problema. Apesar disso, ela estava se envolvendo com ele. Carla afirmou que sempre esteve no controle e agora ele estava mostrando que ela não precisava controlar sempre. Carla tinha medo de que o novo namorado se tornasse mais uma pessoa para ela cuidar, mas estava percebendo que não precisaria ser assim. A terapeuta destacou que uma relação é uma oportunidade de cuidar e ser cuidada ao mesmo tempo.

Maria comparou essa relação de Carla com a relação dela e do ex-marido e disse temer que a de Carla também não desse certo. A intervenção foi feita com o objetivo de incentivar a diferenciação entre mãe e filha. A diferenciação entre indivíduo e família é algo que pode ser entendido como importante para fortalecer Carla, na medida em que fez sentido para ela esta mudança no seu processo terapêutico.

Já no final da sessão, Maria perguntou se estava terminando, pois ela que- ria falar algo na minha frente. Nesse momento, ela segurou a mão de Lucas e disse, se dirigindo a ele:

Meu filho, eu não posso mais cuidar de você como um "bebezão". Você vai ter que se esforçar pra fazer as coisas pra você. Você não vai me ter pra sempre. Nem a sua irmã.

Maria continuou comentando o quanto Lucas tem mudado, mas que ainda tem muita coisa para mudar. Comentou que ele tem que começar a ter mais independência, começar a gastar o dinheiro dele com coisas para ele. Carla mencionou que a terapia foi muito boa e que foi um divisor de águas, principalmente para Maria. Ao nos despedirmos, Carla disse que irá enviar o convite de casamento para a terapeuta.

As mudanças percebidas ao longo do processo foram resultantes da interação entre a família e a terapeuta e da coconstrução de novos sentidos para as relações familiares a partir do processo terapêutico. A família aceitou compartilhar sua história e a partir daí foi possível a criação de novas narrativas dessa história. O problema foi compreendido em termos relacionais e a sua solução, assim como discutiram Rasera e Guanaes (2010), também passou a ser pensada relacionalmente, a partir de responsabilidade compartilhada.

\section{CONSIDERAÇÕES FINAIS}

A partir das considerações feitas sobre o processo, pode-se dizer que a terapia possibilitou mudanças significativas no sistema familiar. Os recursos conversacionais utilizados colaboraram para o cumprimento dos objetivos do processo terapêutico deli- 
mitados em conjunto a partir das expectativas da terapeuta e da família. A reflexividade no sistema terapêutico foi valorizada e o foco da terapia não se concentrou em diagnósticos, e sim no desenvolvimento de novas possibilidades relacionais. A família foi encorajada a explorar visões alternativas sobre suas dificuldades. Priorizou-se o resgate das competências dos indivíduos na resolução das dificuldades experienciadas.

Os procedimentos e técnicas adotados no processo terapêutico foram utilizados dentro de uma postura de reconhecimento e legitimação da configuração familiar. Concordando com Narvaz e Koller (2007), a competência das famílias depende da qualidade das relações estabelecidas e não da sua estrutura ou configuração. Depende das narrativas construídas, sejam de valorização ou desqualificação de suas capacidades. Desta forma, a terapia favoreceu o resgate da autoestima dos membros da família, construção de narrativas alternativas, ampliação das histórias trazidas, externalização de qualidades e reflexões sobre as relações familiares.

Minuchin, Nichols e Lee (2009) apontam que a experiência de vida do terapeuta é parte importante do estilo de terapia que ele desenvolve. A adoção do conjunto de teorias e pressupostos feita pela terapeuta está localizada no contexto de sua história de vida pessoal/profissional. O terapeuta também é integrante do sistema terapêutico. Assim, a partir do momento que se entende que a terapia é um encontro de subjetividades, a subjetividade da terapeuta também fez parte desse processo. Ao mesmo tempo em que mudanças ocorreram na família, esse encontro também teve repercussões na terapeuta. Pode-se citar como exemplo um maior empoderamento enquanto terapeuta de família.

A terapia familiar realizada com apenas um terapeuta foi capaz de possibilitar mudanças. Como destaca Guanaes-Lorenzi (2014, p. 124), no contexto das práticas pós-modernas, "é o reconhecimento e a criação de novas formas de prática para os clientes, membros e comunidades, pesquisadores/profissionais e todos os participantes, que sinaliza práticas efetivas". De acordo com essa autora, práticas que permitem às pessoas superarem problemas identificados servem como evidência de sua efetividade. A análise do processo terapêutico, principalmente a partir dos relatos dos participantes, permite acreditar que a prática clínica desenvolvida ajudou a família a transformar suas relações.

As considerações tecidas neste texto não esgotam as possibilidades de reflexões que podem ser geradas. A complexidade do sistema terapêutico poderá fomentar análises para além das que foram feitas aqui. Entende-se também que muitos pontos poderiam ser aprofundados ou mais bem explorados. Entretanto, priorizou-se a apresentação de um panorama geral do processo terapêutico.

\section{REFERÊNCIAS}

Alves, C. O. (2013). Psicologia e perspectiva feminista: produção de conhecimento, prática e programas de prevenção em saúde mental. Dissertação de Mestrado, Programa de Pós-graduação em Psicologia, Universidade de Brasília, Brasília, DF.

Butler, J. (2014). Problemas de gênero: feminismo e subversão da identidade (R. Aguiar, Trad.). Rio de Janeiro: Civilização Brasileira. (Original publicado em 1990). 
Boscolo, L. \& Bertrando, Pn (2008). Terapia sistêmica individuale. Madrid, ESP: Amorrortu Editores.

Corradi-Webster, C. M. (2014). Ferramentas teórico-conceituais do discurso construcionista. In C. Guanaes-Lorenzi, M. S. Moscheta, C. M. Corradi-Webster, \& L. V. Souza (Orgs.), Construcionismo social: discurso, prática e produção do conhecimento (pp. 50-72). Rio de Janeiro: Instituto Noos.

Couto-Oliveira, V. (2007). Vida de mulher: gênero, pobreza, saúde mental e resiliência. Dissertação de Mestrado, Programa de Pós-graduação em Psicologia, Universidade de Brasília, Brasília, DF.

Davies, B. \& Harré, R. (1990). Positioning: The discursive production of selves. Journal for the Theory of Social Behaviour, 20(1), 43-63. Recuperado de http://onlinelibrary.wiley. com/doi/10.1111/j.1468-5914.1990. tb00174.x/full

Diniz, G. R. S. (1999). Condição feminina - fator de risco para a saúde mental? In M. G. T. Paz \& A. Tamayo (Orgs.). Escola, saúde e trabalho: estudos psicológicos (pp. 181197). Brasília, DF: Editora UnB.

Diniz, G. R. S. (2004). Mulher, trabalho e saúde mental. In C. Wandeley (Org.), O trabalho enlouquece? Um encontro entre a clínica e o trabalho (pp. 105-138). Petrópolis, RJ: Vozes. Diniz, G. R. S. \& Alves, C. O. (2014). Gênero, conjugalidades e violência: uma proposta de intervenção sistêmica-feminista. In C. Stevens, S. R. Oliveira, \& V. Zanello (Orgs.), Estudos feministas e de gênero: articulações e perspectivas (pp. 161-175). Florianópolis: Ed. Mulheres. Recuperado de http://www.repositorio.unb.br/bitstream/10482/16349/1/LIVRO_EstudosFeministasedeGeneroArticula\%C3\%A7\%C3\%B5es.pdf
Evans, K. M., Kincade, E. A., \& Seem, S. R. (2011). Introduction to feminist therapy: Strategies for social and individual change. Thousand Oaks, CA: SAGE Publications, Inc.

Giffin, K. (2005). A inserção dos homens nos estudos de gênero: contribuições de um sujeito histórico. Ciência e Saúde Coletiva, 10(1), 4757. Recuperado de http://www.scielo.br/pdf/csc/v10n1/a05v10n1

Grandesso, M. A. (2000). Sobre a reconstrução do significado: uma análise epistemológica e hermenêutica da prática clínica. São Paulo: Casa do Psicólogo.

Grandesso, M. A. (2009). Desenvolvimentos em terapia familiar: das teorias às práticas e das práticas às teorias. In Osório, L. C \& Valle, M. E. P. (Orgs.), Manual de terapia familiar (pp. 104-118). Porto Alegre: ArtMed.

Greene, K. \& Bogo, M. (2002). The different faces of intimate partner violence: Implications for assessment and treatment. Journal of Marital and Family Therapy, 28(4), 455-466. Recuperado de http://onlinelibrary.wiley.com/ doi/10.1111/j.1752-0606.2002. tb00370.x/full

Guanaes-Lorenzi, C. (2014). Construcionismo social: tensões e possibilidades de um movimento em permanente construção. In C. Guanaes-Lorenzi, M. S. Moscheta, C. M. Corradi-Webster, \& L. V. Souza (Orgs.), Construcionismo social: discurso, prática e produção do conhecimento (pp. 89-104). Rio de Janeiro: Instituto Noos.

Martins, P. P. S., Santos, M. V.y \& Guanaes-Lorenzi, C. (2014). Participação da família no tratamento em saúde mental: histórias sobre diálogo e inclusão. In C. Guanaes-Lorenzi, M. S. Moscheta, C. M. Corradi-Webs- 
ter, \& L. V. Souza (Orgs.), Construcionismo social: discurso, prática e produção do conhecimento (pp. 89104). Rio de Janeiro: Instituto Noos. Mayorga, C.n Coura, Ans Miralles, No, \& Cunha, V. M. (2013). As críticas ao gênero e a pluralização do feminismo: colonialismo, racismo e política heterossexual. Revista Estudos Feministas, 21(2), 463-484. Recuperado de http://www.jstor.org/stable/24328285? seq=1\#page scan tab contents

Minuchin, S., Nichols, M., \& Lee, Way-Yung. (2009). Famílias e casais: do sintoma ao sistema. Porto Alegre: Artmed.

Moscheta, M. S. (2014). A pós-modernidade e o contexto para a emergência do discurso construcionista social. In C. Guanaes-Lorenzi, M. S. Moscheta, C. M. Corradi-Webster, \& L. V. Souza (Orgs.), Construcionismo social: discurso, prática e produção do conhecimento (pp. 23-47). Rio de Janeiro: Instituto Noos.

Narvaz, M. G \& Koller, S. H. (2007). Feminismo e terapia: a terapia feminista da família - por uma psicologia comprometida. Psicologia Clínica, 19(2), 117-131. Recuperado de http://www.scielo.br/pdf/pc/ v19n2/a09v19n2

Neves, S. \& Nogueirra, C. (2004). Terapias feministas, intervenção psicológica e violências na intimidade: uma leitura feminista crítica. Psychologica, 36, 15-32.

Paschoal, V. N. \& Grandesso, M. (2014). O uso de metáforas em terapia narrativa: facilitando a construção de novos significados. Nova Perspectiva Sistêmica, 48, 24-43.

Paula-Ravagnani, G. S. (2015). Difusão do construcionismo social entre terapeutas familiares: desafios e potencialidades. Dissertação de Mestrado, Programa de Pós-graduação em Psicologia, Universidade de São Paulo, Ribeirão Preto, SP.

Perelberg, R. J. (1994). Igualdade, assimetria e diversidade: sobre as conceitualizações dos sexos. In R. J. Perelberg \& A. C. Miller (Orgs.), Os sexos e o poder nas famílias (pp. 4771). Rio de Janeiro: Imago.

Rasera, E. F. \& Guanaes, C. (2010). Momentos marcantes na construção da mudança em terapia familiar. Psicologia Teoria e Pesquisa, 26(2), 315-322.

Scott, J. (1995). Gênero, uma categoria útil de análise histórica. Educação \& Realidade, 20(2), 71-99.

Sousa, L. V. (2014). Discurso construcionista social: uma apresentação possível. In C. Guanaes-Lorenzi, M. S. Moscheta, C. M. Corradi-Webster, \& L. V. Souza (Orgs.), Construcionismo social: discurso, prática $e$ produção do conhecimento (pp. 5072). Rio de Janeiro: Instituto Noos.

Vianna, C. (2012). Gênero e psicologia clínica: risco e proteção na saúde mental de mulheres. Tese de Doutorado, Programa de Pós-graduação em Psicologia, Universidade de Brasília, Brasília, DF.

Walters, M. (1994). Uma perspectiva feminista para a terapia de família. In R. J. Perelberg \& A. C. Miller (Orgs.), Os sexos e o poder nas famílias (pp. 27-46). Rio de Janeiro: Imago.

Worell, J. \& Johnson, D. (2001). Therapy with women: Feminist frameworks. In R. K. Unger (Ed.), Handbook of the psychology of women and gender (pp. 317-329). New York:Wiley.

Zanello, V. (2010). Mulheres e loucura: questões de gênero para a psicologia clínica. In C. Stevens, K. C. T. Brasil, T. M. C. Almeida, \& V. Zanello, (Orgs.), Gênero e feminismos: convergências (in) disciplinares (pp. 307-320). Brasília, DF: EX Libris. 
Zanello, V. \& Bukowitz, B. (2011). Loucura e cultura: uma escuta das relações de gênero nas falas de pacientes psiquiatrizados. Revista Labrys,

\section{CLÁUDIA DE OLIVEIRA ALVES}

É psicóloga, doutoranda e mestre em Psicologia Clínica e Cultura na Universidade de Brasília (UnB). Docente no curso de Graduação em Psicologia da Universidade Paulista (UNIP), Brasília, DF.

E-mail: claoalves@hotmail.com

\section{ANALICE DE SOUSA ARRUDA VINHAL DE CARVALHO}

É mestre em Ciências da Família, BYU/EUA. Doutoranda em Psicologia Clínica e Saúde, na Pontifícia Universidade Católica de Goiás. Docente no Curso de Graduação em Psicologia da Universidade Paulista (UNIP), Goiânia, GO.

E-mail: analicearrudavinhal@gmail. com 